\title{
Facile Synthesis, Microstructure, and Gas Sensing Properties of $\mathrm{NdCoO}_{3}$ Nanoparticles
}

\author{
Lorenzo Gildo-Ortiz, ${ }^{1}$ Héctor Guillén-Bonilla, ${ }^{2}$ \\ Juan Reyes-Gómez, ${ }^{3}$ Verónica María Rodríguez-Betancourtt, ${ }^{4}$ \\ M. de la L. Olvera-Amador, ${ }^{5}$ Sandra Irene Eguía-Eguía, ${ }^{1}$ \\ Alex Guillén-Bonilla, ${ }^{6}$ and Jaime Santoyo-Salazar ${ }^{7}$ \\ ${ }^{1}$ Nanociencias y Nanotecnología, Centro de Investigación y de Estudios Avanzados del Instituto Politécnico Nacional, \\ 07360 México City, Mexico \\ ${ }^{2}$ Departamento de Ingeniería de Proyectos, CUCEI, Universidad de Guadalajara, 44410 Guadalajara, JAL, Mexico \\ ${ }^{3}$ Facultad de Ciencias, Universidad de Colima, 28045 Colima, COL, Mexico \\ ${ }^{4}$ Departamento de Química, CUCEI, Universidad de Guadalajara, 44410 Guadalajara, JAL, Mexico \\ ${ }^{5}$ Departamento de Ingeniería Eléctrica-SEES, Centro de Investigación y de Estudios Avanzados del Instituto Politécnico Nacional, \\ 07360 México City, Mexico \\ ${ }^{6}$ Departamento de Ciencias Computacionales e Ingenierías, CUVALLES, Universidad de Guadalajara, 46600 Ameca, JAL, Mexico \\ ${ }^{7}$ Departamento de Física, Centro de Investigación y de Estudios Avanzados del Instituto Politécnico Nacional, \\ 07360 México City, Mexico
}

Correspondence should be addressed to Lorenzo Gildo-Ortiz; lorenzo.gildo@gmail.com

Received 15 April 2017; Revised 27 June 2017; Accepted 6 July 2017; Published 3 August 2017

Academic Editor: Oscar Perales-Pérez

Copyright (C) 2017 Lorenzo Gildo-Ortiz et al. This is an open access article distributed under the Creative Commons Attribution License, which permits unrestricted use, distribution, and reproduction in any medium, provided the original work is properly cited.

$\mathrm{NdCoO}_{3}$ nanoparticles were successfully synthesized by a simple, inexpensive, and reproducible solution method for gas sensing applications. Cobalt nitrate, neodymium nitrate, and ethylenediamine were used as precursors and distilled water as solvent. The solvent was evaporated later by means of noncontinuous microwave radiation at $290 \mathrm{~W}$. The obtained precursor powders were calcined at $200,500,600$, and $700^{\circ} \mathrm{C}$ in a standard atmosphere. The oxide crystallized in an orthorhombic crystal system with space group Pnma (62) and cell parameters $a=5.33 \AA, b=7.52 \AA$, and $c=5.34 \AA$. The nanoparticles showed a diffusional growth to form a network-like structure and porous adsorption configuration. Pellets prepared from $\mathrm{NdCoO}_{3}$ were tested as gas sensors in atmospheres of carbon monoxide and propane at different temperatures. The oxide nanoparticles were clearly sensitive to changes in gas concentrations $(0-300 \mathrm{ppm})$. The sensitivity increased with increasing concentration of the gases and operating temperatures $\left(25,100,200\right.$, and $\left.300^{\circ} \mathrm{C}\right)$.

\section{Introduction}

Perovskite-type oxides with $\mathrm{ABO}_{3}$ structure and related materials constitute a group of compounds with a significant technological value because of their interesting physical and chemical properties [1-8]. Within this family of compounds, cobaltites, of general formula $\mathrm{RECoO}_{3}(\mathrm{RE}=$ rare earth like La, Nd, Gd, etc.), have been widely studied for their important applications as catalysts, thermoelectric compounds, cathodes for solid-oxide fuel-cells, and gas sensors [9-12]. Several investigations have shown that the presence of cobalt ions, with different oxidation states, plays an important role in the transport properties and catalytic activity of perovskites [13, 14]. Furthermore, the ability to modify their microstructures, such as porosity, distribution, shape, and particle size can induce changes in their physical properties $[15,16]$. Owing to the nanometric size of the perovskite particles, many applications are potentiated. Nowadays, various synthesis methods are investigated in order to achieve control of the size and shape of the nanoparticles. These methods include 
sol-gel routes, hydrothermal, solid-state reaction, coprecipitation, spray pyrolysis, solution-combustion processes, and physical vapor deposition [17]. In particular, "soft" chemistry methods allow a better control on the stoichiometry and a reduction of the synthesis temperature, which permits obtaining homogeneous nanoparticles [18].

The perovskite-type oxides are of particular interest in the field of gas sensors because they exhibit a high melting point, chemical stability under reducing and oxidizing environments, and a dependency of the partial pressure of oxygen on the concentration of point defects [19]. Among the mixed valence perovskites, $\mathrm{NdCoO}_{3}$ stands out as a strong candidate for gas sensors because it has a high sensitivity to gases, mainly carbon monoxide (CO) $[20,21]$. One reason for the high response in gases is that the oxide crystallizes in a perovskite-type structure, where neodymium ions $\left(\mathrm{Nd}^{3+}\right)$ are dodecahedrally coordinated, while cobalt has an octahedral coordination but not an integer oxidation state [20]. This latter occurs because cobalt can fluctuate between two stable oxidation states producing oxygen-deficient perovskites $\left(\mathrm{RECoO}_{3-\delta}\right)$ with a mixed valence state for cobalt: $\mathrm{Co}^{2+}$ and $\mathrm{Co}^{3+}$, where $\mathrm{Co}^{3+}$ dominate [22]. The equilibration of oxygen in the gas phase with oxygen vacancies in the oxide favors the response of the perovskite as gas sensor [19]. However, it is necessary to optimize the performance of this material giving emphasis to its microstructure in order to achieve a functional behavior as gas sensor. In particular, the development of sensors for the detection of carbon monoxide (CO) and gaseous hydrocarbons requires special attention because of their potential hazards [23]. CO is one of the most abundant toxic gases and is characterized by being odorless and colorless. Prolonged exposure to this gas can cause damage to the human body and even death, while gaseous hydrocarbons are usually flammable gases with no odor or color. In this regard, one of the objectives of this work was to synthesize $\mathrm{NdCoO}_{3}$ nanoparticles by a simple method using relatively low calcination temperatures. Another objective was to measure the response of the material's sensitivity in $\mathrm{CO}$ and propane, several concentrations of them, and operating temperatures.

\section{Experimental Procedures}

2.1. $\mathrm{NdCoO}_{3}$ Synthesis. $\mathrm{NdCoO}_{3}$ nanoparticles with perovskite structure were synthesized by a solution method assisted by microwave radiation. 0.004 mole of $\mathrm{Nd}\left(\mathrm{NO}_{3}\right)_{3} \cdot 6 \mathrm{H}_{2} \mathrm{O}$ (Aldrich, 99.9\%), 0.004 mole of $\mathrm{Co}\left(\mathrm{NO}_{3}\right)_{2} \cdot 6 \mathrm{H}_{2} \mathrm{O}$ (Jalmek, $98.6 \%$ ), and 0.030 mole of ethylenediamine (Sigma, $\geq 99.5 \%$ ) were separately dissolved in distilled water. The cobalt nitrate and ethylenediamine solutions were mixed slowly and the mixture was later stirred for $20 \mathrm{~min}$ at $375 \mathrm{rpm}$. The neodymium nitrate solution was slowly added to the mixture and the stirring continued for $24 \mathrm{~h}$ at room temperature. Evaporation of the solvent was carried out using noncontinuous microwave radiation at $290 \mathrm{~W}$ using a domestic microwave oven (LG, model MS1147). The microwave radiation was applied in steps of 60 to $90 \mathrm{~s}$ to maintain the suspension's temperature below $90^{\circ} \mathrm{C}$. Control of temperature and exposure times was needed to prevent loss of material. The paste produced from evaporation was dried at $200^{\circ} \mathrm{C}$ for $8 \mathrm{~h}$ in a normal atmosphere, and the obtained powders were divided into three parts and they were calcined at 500, 600, and $700^{\circ} \mathrm{C}$, respectively. For this, a heating rate of $100^{\circ} \mathrm{C} / \mathrm{h}$ was employed with a residence time of $5 \mathrm{~h}$. The heat treatment was performed in a programmable oven $\left(\right.$ Vulcan $\left.^{\mathrm{TM}}\right)$ temperature control.

2.2. Characterization of $\mathrm{NdCoO}_{3}$ Powders. All the calcined powders were analyzed by X-ray powder diffraction (XRD) at room temperature using a Rigaku SmartLab diffractometer, with $\mathrm{CuK \alpha}$ radiation and nickel filter. The $2 \theta$ scanning range was from 20 to $70^{\circ}$, with steps of $0.02^{\circ}$ and a duration of $1 \mathrm{~s}$ per step. The material's microstructure was analyzed by scanning electron microscopy (SEM, JEOL JSM-6390LV) in high vacuum mode using the secondary electron (SE) emission. The surface chemical composition was analyzed by energy dispersive X-ray spectroscopy (EDS-SEM) with a Bruker 5010 XFlash detector. To observe the nanoparticles, a transmission electron microscope (TEM, JEOL JEM-2010) with an accelerating voltage of $200 \mathrm{kV}$ was employed. For this, a representative sample of the powder was used, which was dispersed in isopropyl alcohol for $5 \mathrm{~min}$ and placed on a copper grid. The surface area of the powders was assessed by nitrogen physisorption at $77 \mathrm{~K}$ using a Minisorp II BEL Japan equipment. Prior to the nitrogen adsorption process, the chamber with the sample was degassed and maintained under vacuum for $24 \mathrm{~h}$ at room temperature. The powder topology was analyzed by atomic force microscopy (AFM) using a JSPM-5200 microscope from JEOL under intermittent contact operations under normal pressure conditions.

2.3. Gas Sensitivity Tests. The sensitivity tests of the $\mathrm{NdCoO}_{3}$ were performed in atmospheres of carbon monoxide $(\mathrm{CO})$ and propane $\left(\mathrm{C}_{3} \mathrm{H}_{8}\right)$. The electrical resistance of $\mathrm{NdCoO}_{3}$ pellets with a diameter of $12 \mathrm{~mm}$ and a thickness of $500 \mu \mathrm{m}$ was measured. The pellets were made with $0.3 \mathrm{~g}$ of $\mathrm{NdCoO}_{3}$ powders at a pressure of 10 tons during $30 \mathrm{~min}$ using a Simplex Ital Equip-25 tons pressing machine. Two ohmic contacts were placed on the surface of the pellets using colloidal silver paint (Alfa Aesar, >99\%). The pellets were placed into a measuring chamber with a vacuum capacity of $10^{-3}$ torr. The gas concentration inside the chamber was electronically monitored by a Leybold (model TM20) vacuum gauge. The fed gas concentrations were $0,5,50,100,200$, and $300 \mathrm{ppm}$. The operating temperature was electronically controlled using a type J thermocouple with four fixed values: $25,100,200$, and $300^{\circ} \mathrm{C}$. The electrical resistance was recorded using a Keithley 2001 digital multimeter. The sensitivity $(S)$ was calculated by the relative difference in electrical conductances using the expression $S=\left(G_{G}-G_{0}\right) / G_{0}$, where $G_{G}$ and $G_{0}$ denote electrical conductances in the sampled gas $\left(\mathrm{CO}\right.$ or $\mathrm{C}_{3} \mathrm{H}_{8}$ ) and air, respectively. Figure 1 shows a diagram of the system used for the material's characterization in the gases. 


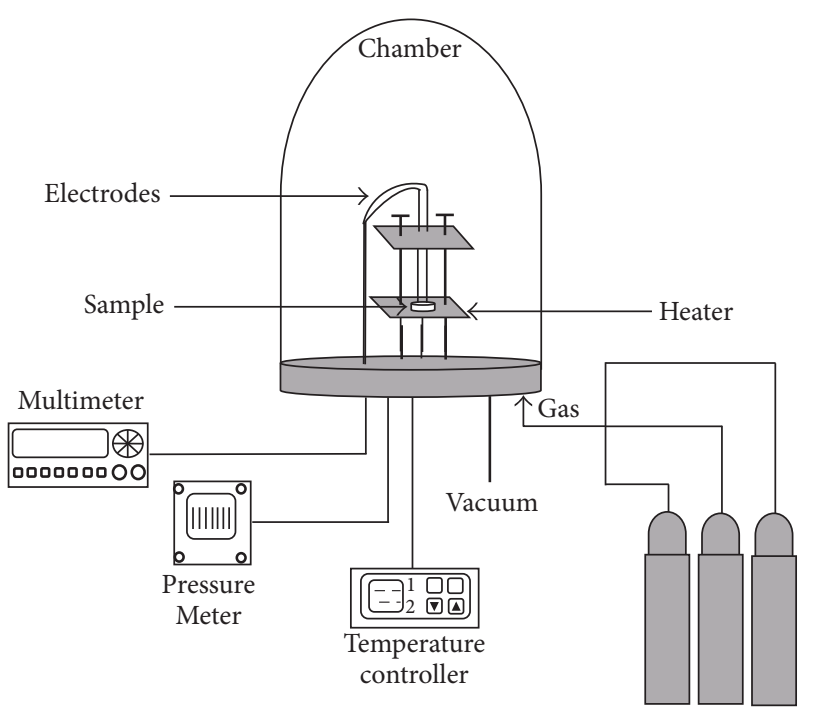

FIGURE 1: Schematic of the system used to measure the electrical response in a controlled atmosphere and temperature environment.

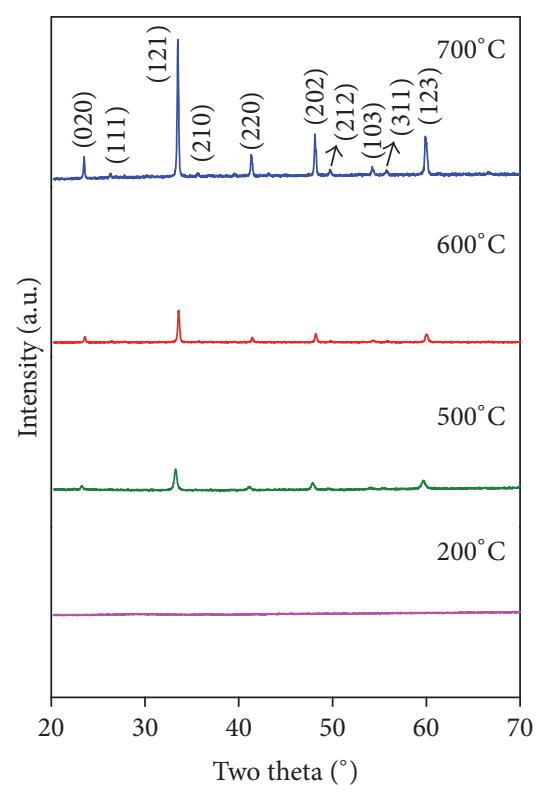

FIGURE 2: X-ray diffraction pattern of the powders obtained after calcination at $200,500,600$, and $700^{\circ} \mathrm{C}$.

\section{Results and Discussion}

3.1. XRD Analysis. Figure 2 shows the X-ray diffraction patterns of the calcined powders at $200,500,600$, and $700^{\circ} \mathrm{C}$. From the spectra array it can be observed that paste calcined at $200^{\circ} \mathrm{C}$ is amorphous, since the diffractogram does not show defined peaks. The spectra of powders calcined at 500,600, and $700^{\circ} \mathrm{C}$ present the diffraction peaks corresponding to the $\mathrm{NdCoO}_{3}$ phase with perovskite structure. These peaks were observed at the $2 \theta$ angular positions $23.6^{\circ}, 26.5^{\circ}, 33.6^{\circ}, 35.8^{\circ}$, $41.5^{\circ}, 48.3^{\circ}, 49.8^{\circ}, 54.3^{\circ}, 55.8^{\circ}$, and $60.0^{\circ}$, which are indexed according to the reference from The International Centre for Diffraction Data, ICDD, 00-052-1279-PDF as the following
TABLE 1: Comparison of the main synthesis methods for $\mathrm{NdCoO}_{3}$.

\begin{tabular}{|c|c|c|c|c|}
\hline Material & Method & $\begin{array}{c}\text { Temperature } \\
\left({ }^{\circ} \mathrm{C}\right)\end{array}$ & $\begin{array}{c}\text { Time } \\
\text { (h) }\end{array}$ & Ref. \\
\hline $\mathrm{NdCoO}_{3}$ & Sol-gel & 1100 & No data & {$[20]$} \\
\hline $\begin{array}{l}\mathrm{ACoO}_{3}(\mathrm{~A}=\mathrm{Pr} \\
\mathrm{Nd}, \mathrm{Sm}, \mathrm{Gd})\end{array}$ & Molten salt & 1100 & 3 & {$[24]$} \\
\hline $\begin{array}{l}\mathrm{ACoO}_{3}(\mathrm{~A}=\mathrm{Pr} \\
\mathrm{Nd}, \mathrm{Tb}, \mathrm{Dy})\end{array}$ & $\begin{array}{c}\text { Ball } \\
\text { milling }\end{array}$ & 1000 & 8 & [25] \\
\hline $\mathrm{NdCo}(\mathrm{Ca}, \mathrm{Sr}) \mathrm{O}_{3}$ & Ceramic & $900-1050$ & 24 & [26] \\
\hline $\mathrm{NdCoO}_{3}$ & $\begin{array}{c}\text { Paste } \\
\text { calcination }\end{array}$ & 900 & 4 & [27] \\
\hline $\mathrm{NdCoO}_{3}$ & Solution & 700 & 5 & This work \\
\hline
\end{tabular}

crystal planes: (020), (111), (121), (210), (220), (202), (212), (103), (311), and (123), respectively. The $\mathrm{NdCoO}_{3}$ crystallized in an orthorhombic system with space group Pnma (62) and cell parameters $a=5.33 \AA, b=7.52 \AA$, and $c=5.34 \AA$. At higher calcination temperatures, the peaks in the spectra are of higher amplitude, better defined, and with a relative low level of noise, all of which are associated with a better crystallinity, especially the sample obtained at $700^{\circ} \mathrm{C}$.

We found in this work that, using the solution method, $\mathrm{NdCoO}_{3}$ powders can be synthesized at a relative low temperature of $700^{\circ} \mathrm{C}$, which is lower than those used in others methods to produce these compounds. For example, using the sol-gel method (in the presence of urea), $\mathrm{NdCoO}_{3}$ was obtained using a sintering temperature of $1100^{\circ} \mathrm{C}$ [20]; the compound series $\mathrm{ACoO}_{3}$ has been synthesized by calcining at $1100^{\circ} \mathrm{C}$ per $3 \mathrm{~h}$ (for $\mathrm{A}=\mathrm{Pr}, \mathrm{Nd}, \mathrm{Sm}$, and Gd) [24], and at $700^{\circ} \mathrm{C}$ per $5 \mathrm{~h}$ followed by a sintering step at $1000^{\circ} \mathrm{C}$ per $8 \mathrm{~h}$ (for $\mathrm{A}=\mathrm{Pr}, \mathrm{Nd}, \mathrm{Tb}$, and $\mathrm{Dy}$ ) [25]; through the conventional solid-state reaction method, $\mathrm{NdCoO}_{3}, \mathrm{Nd}_{0.8} \mathrm{Ca}_{0.2} \mathrm{CoO}_{3}$, and $\mathrm{Nd}_{0.8} \mathrm{Sr}_{0.2} \mathrm{CoO}_{3}$ have been synthesized at the temperatures $900-1050^{\circ} \mathrm{C}$ with calcination times of $24 \mathrm{~h}$ [26]; $\mathrm{NdCoO}_{3}$ has been also synthesized through calcination at $900^{\circ} \mathrm{C}$ from a precursor reactive paste [27]. Table 1 shows a summary of the methods commonly employed to synthesize this perovskite. After reviewing literature, the method used in this work can be considered as a simple and efficient route to synthesize $\mathrm{NdCoO}_{3}$.

3.2. SEM Analysis and $\mathrm{N}_{2}$ Adsorption. The following results were obtained for the $\mathrm{NdCoO}_{3}$ powders obtained at $700^{\circ} \mathrm{C}$. Figures $3(\mathrm{a})-3(\mathrm{~d})$ show typical SEM micrographs of the $\mathrm{NdCoO}_{3}$ powders. The images were taken at these magnifications: (a) 500x, (b) 2000x, (c) 5000x, and (d) 10000x (inset: 30000x). It can be seen in Figures 3(a) and 3(b) that the oxide's surface has a lot of different sized pores (in a range 0.5 to $25 \mu \mathrm{m}$ ), which confers it a sponge-like morphology. In Figures 3(c) and 3(d), at higher magnification, it can be clearly observed an agglomeration of particles with high connectivity between them, forming a network-like structure. In addition, smaller pores can be observed (with a size of about $0.2 \mu \mathrm{m}$ ). This porosity is also attributable to the gases released during thermal decomposition of organic matter, mainly water vapor, $\mathrm{NO}_{x}$, and $\mathrm{CO}_{2}[28]$. 

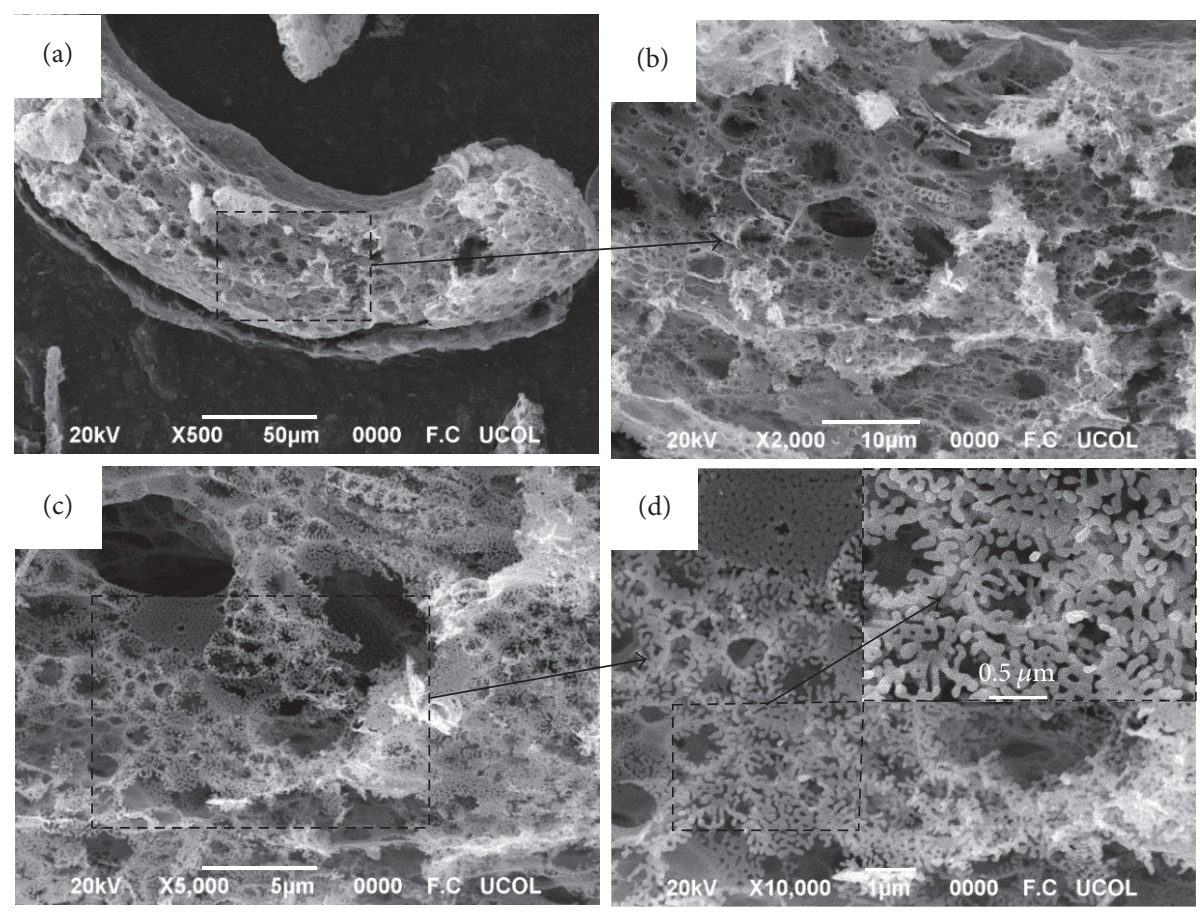

Figure 3: SEM images of $\mathrm{NdCoO}_{3}$ powders (synthesized at $700^{\circ} \mathrm{C}$ ) at several magnifications: (a) 500x, (b) 2000x, (c) 5000x, and (d) 10000x (inset: 30000x).

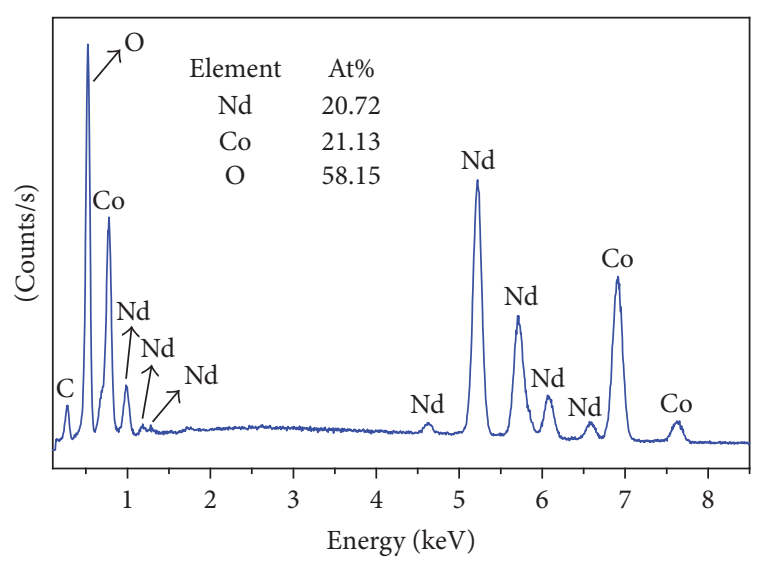

Figure 4: EDS-SEM spectrum of the $\mathrm{NdCoO}_{3}$ powders synthesized at $700^{\circ} \mathrm{C}$.

Figure 4 shows a typical EDS-SEM spectrum obtained from the $\mathrm{NdCoO}_{3}$ powders. In this spectrum, the characteristic $\mathrm{Nd}$, Co, and $\mathrm{O}$ peaks, according to the material's chemical composition, can be identified. For neodymium (Nd), the peak of greatest intensity in the spectrum corresponds to the characteristic line $\mathrm{L} \alpha$, whose energy is $5.22 \mathrm{keV}$. For cobalt (Co), three peaks located at $0.77,6.92$, and $7.65 \mathrm{keV}$ correspond to the characteristic $\mathrm{L} \alpha, \mathrm{K} \alpha$, and $\mathrm{K} \beta$ lines, respectively. For oxygen $(\mathrm{O})$, the corresponding line is $\mathrm{K} \alpha$, whose energy is $0.53 \mathrm{keV}$. The peak located at $0.28 \mathrm{KeV}$ denotes the presence of carbon (C), which is a residue of the thermal decomposition of organic matter, this being one of

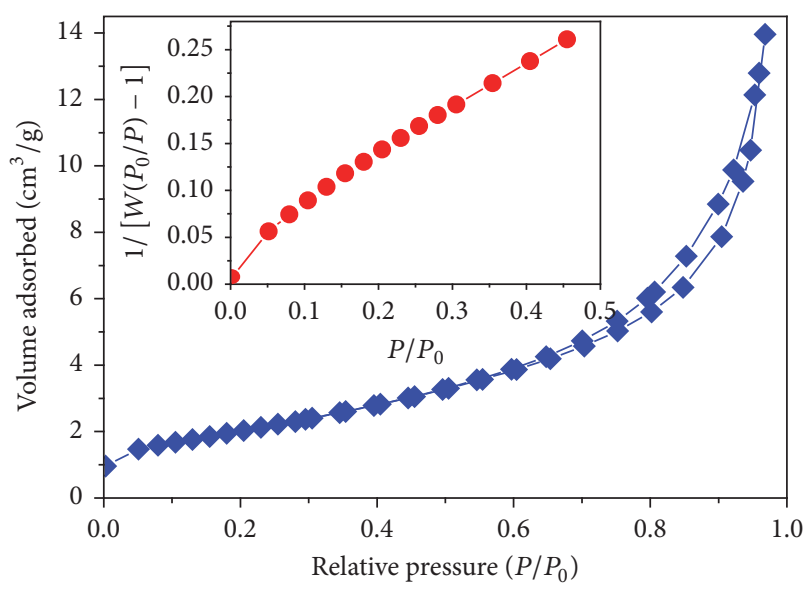

Figure 5: $\mathrm{N}_{2}$ adsorption isotherm of the $\mathrm{NdCoO}_{3}$ powders synthesized at $700^{\circ} \mathrm{C}$ (inset: BET plot).

the disadvantages of using organic reagents in the preparation of inorganic materials [29]. In addition, the EDS-SEM elemental composition ( $\mathrm{Nd}: \mathrm{Co}: \mathrm{O}$ at. \% 20.72:21.13:58.15) corresponds nearly to the theoretical atomic composition of the $\mathrm{NdCoO}_{3}$ (Nd: $\mathrm{Co}: \mathrm{O}$ at. \% $20: 20: 60$ ). The slight deviation can be attributed to traces of metal oxides remaining in the sample.

Figure 5 shows the $\mathrm{N}_{2}$ adsorption isotherm of the $\mathrm{NdCoO}_{3}$ powders at $77 \mathrm{~K}$ and the corresponding BET plot (inset). The shape of the isotherm was characterized as type II according to IUPAC's classification; this isotherm, which shows a weak hysteresis, is typically obtained in the 


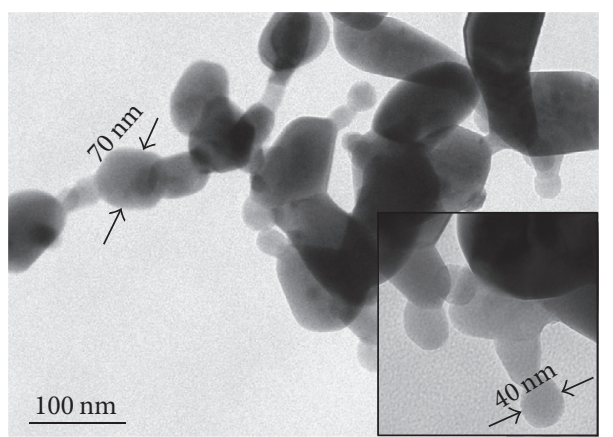

(a)

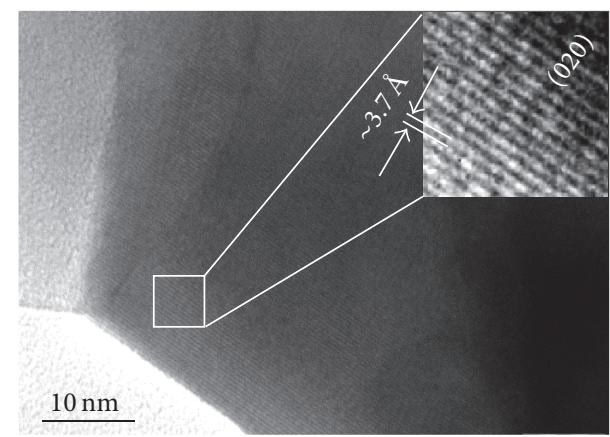

(c)

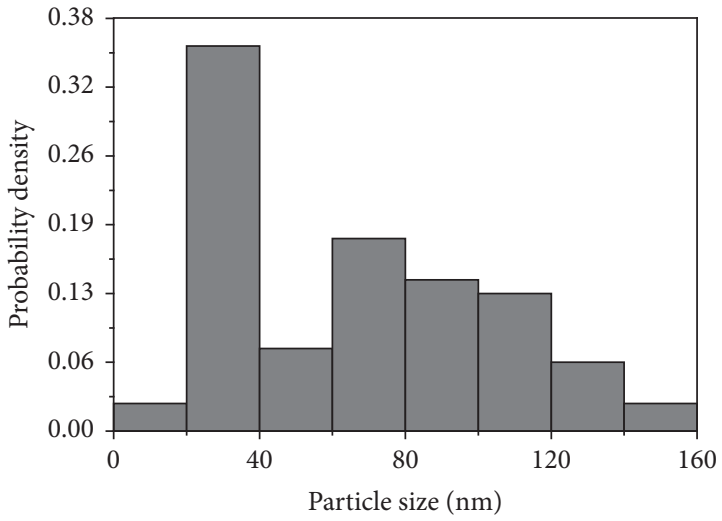

(b)

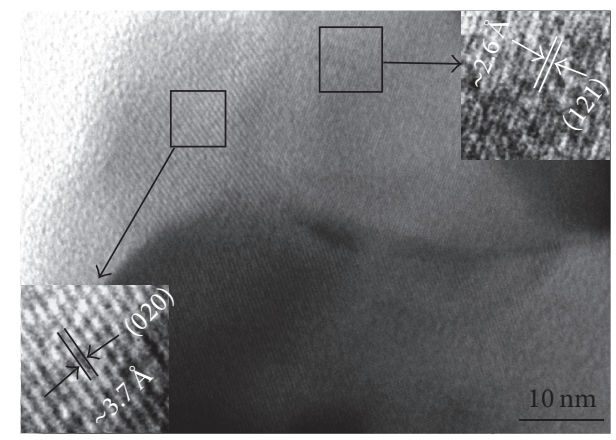

(d)

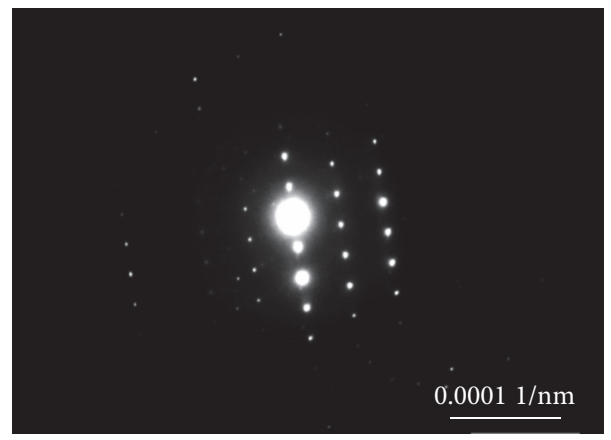

(e)

FIGURE 6: TEM analysis of $\mathrm{NdCoO}_{3}$ powders: (a) $\mathrm{NdCoO}_{3}$ nanoparticles, (b) particle size distribution, (c-d) HRTEM images showing the lattice fringes, and (e) electron diffraction pattern.

case of macroporous solids. The specific surface area was of $7.52 \mathrm{~m}^{2} / \mathrm{g}$. In general, these oxides exhibit relatively low surface areas: in the range of 3 to $14 \mathrm{~m}^{2} / \mathrm{g}$ [30-32]. Our result agrees well in this range.

3.3. TEM Analysis. Figures 6(a)-6(e) show TEM images of the $\mathrm{NdCoO}_{3}$ synthesized at $700^{\circ} \mathrm{C}$ and the particle size distribution. From Figure $6(\mathrm{a})$ it is clear that the $\mathrm{NdCoO}_{3}$ powders are comprised of nanometer sized particles, which possess an irregular shape and are connected to each other, in agreement with the SEM analysis (Figure 3). According to the analysis of multiple TEM images, where the particles were clearly identifiable, it was estimated that their size is in the range of 17 to $151 \mathrm{~nm}$; about $80 \%$ of the particles are within the range of 17 to $100 \mathrm{~nm}$; their average size is $66 \mathrm{~nm}$ with a standard deviation of $37 \mathrm{~nm}$ (Figure 6(b)). Figures 6(c) and 6(d) show images obtained by high-resolution transmission electron microscopy (HRTEM), where fringes can be seen on the material's crystal lattice. These images reveal that the interplanar distances are about 2.6 and $3.7 \AA$ (inset in Figures $6(\mathrm{c})$ and $6(\mathrm{~d}))$, corresponding to planes (121) and (020), respectively, similar to the maximum diffraction angle of $\sim 33.6$ and $\sim 23.6^{\circ}(2 \theta)$ obtained by XRD. Figure $6(\mathrm{e})$ shows an electron diffraction pattern made on a number of nanoparticles. This result confirmed the crystallinity of the powders previously analyzed by XRD and verified the local crystallinity of $\mathrm{NdCoO}_{3}$ sample. 

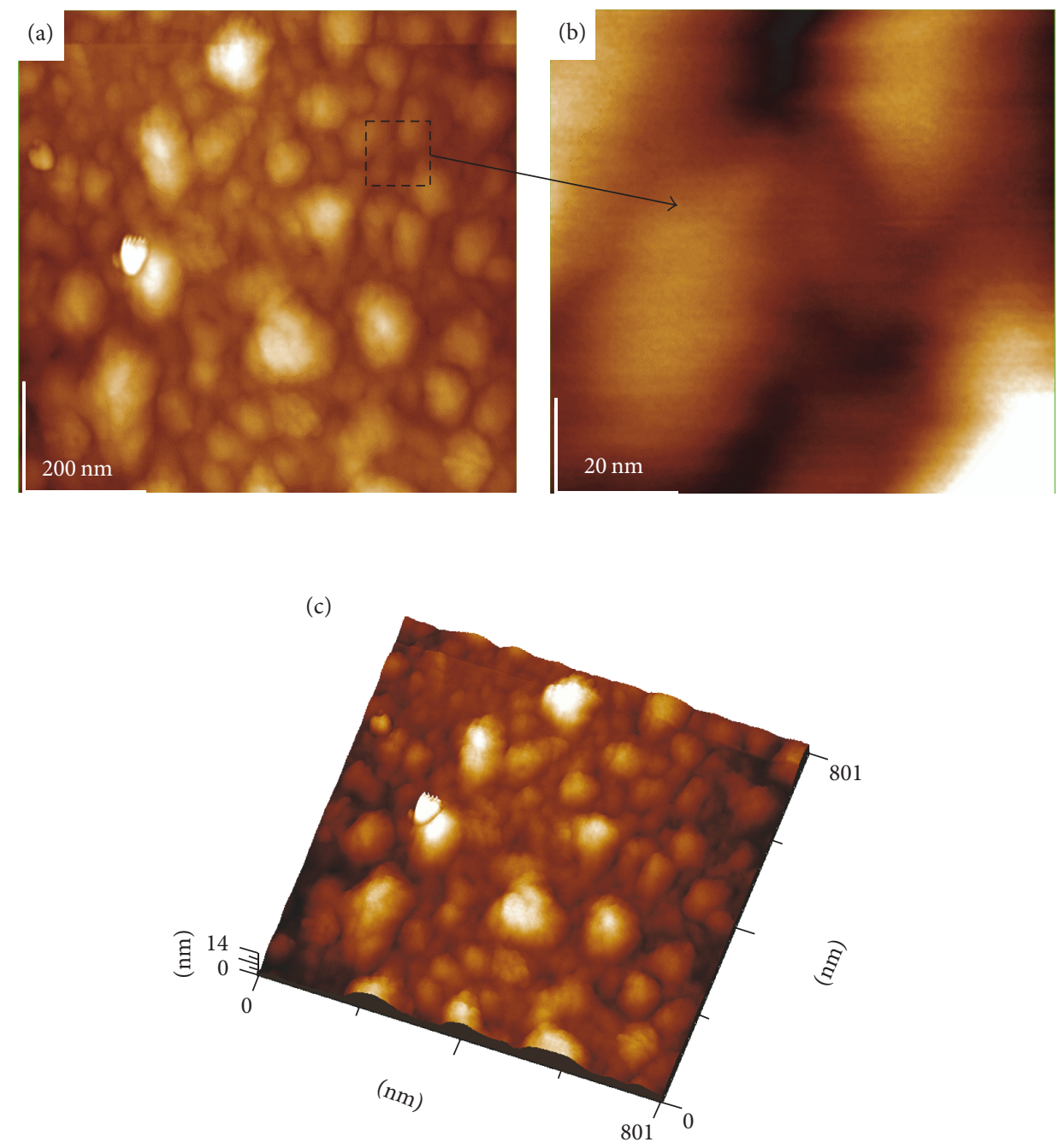

Figure 7: AFM morphological images (a-b) $2 \mathrm{D}$ and (c) $3 \mathrm{D}$ of $\mathrm{NdCoO}_{3}$ powders synthesized at $700^{\circ} \mathrm{C}$.

In some studies, chelating and structure directing agents are employed for controlling the size and shape of the particles. In particular, ethylenediamine is a known chelating agent, which reacts with transition metals yielding coordination compounds [29]. This has been taken advantage of as a strategy for the anisotropic growth of II-VI compound semiconductors such as $\mathrm{ZnS}, \mathrm{ZnSe}$, and CdS [33, 34]. In those studies, the ethylenediamine forms complexes with transition metals, which connect each other, and 1D structures like nanowires and nanotubes are obtained through a condensation reaction [34]. Recently, there have been synthesized mixed oxides with trirutile-type structure by "soft" chemistry methods in the presence of ethylenediamine, for example: $\mathrm{MgSb}_{2} \mathrm{O}_{6}$ nanorods [35], nanostructured $\mathrm{ZnSb}_{2} \mathrm{O}_{6}$ microbars [36], and interconnected (through neck-like structures) mesoporous $\mathrm{CoSb}_{2} \mathrm{O}_{6}$ nanoparticles [37]. We found by using our proposed method that $\mathrm{NdCoO}_{3}$ nanoparticles can be processed with sponge-like morphology to form long chains due to the connectivity between them. The microstructure of these materials is influenced by the amine, which is incorporated and contributes to form inorganic network, acting as a template. Finally subsequently yielding nanocrystals can be tailored in porous adsorption configuration [34]. These morphologies follow the crystallization principles described by Lamer and Dinegar [30, 38].

3.4. AFM Analysis. Figures $7(\mathrm{a})-7(\mathrm{c})$ present the global topography from $\mathrm{NdCoO}_{3}$ powders obtained at $700^{\circ} \mathrm{C}$ by tapping mode AFM. The surface is formed by agglomerates of nanoparticles, which are able to leave spaces in the nanoparticles neighborhood. The scanned area indicates a RMS mean roughness of approximately $1.76 \mathrm{~nm}$. The estimated particle size is about 30 to $150 \mathrm{~nm}$. These results are consistent with those obtained from TEM analysis (Figure 6).

3.5. Gas Sensitivity. Figure 8 shows the sensitivity graph of $\mathrm{NdCoO}_{3}$ depending on the (a) $\mathrm{CO}$ concentration and (b) the operation temperature. At room temperature $\left(25^{\circ} \mathrm{C}\right)$, no significant changes were recorded in the electrical resistance of the material, so the sensitivity was zero for all gas concentrations. However, variations at the temperatures 100, 200 , and $300^{\circ} \mathrm{C}$ were detected. Inset in Figure $8(\mathrm{~b})$ shows 

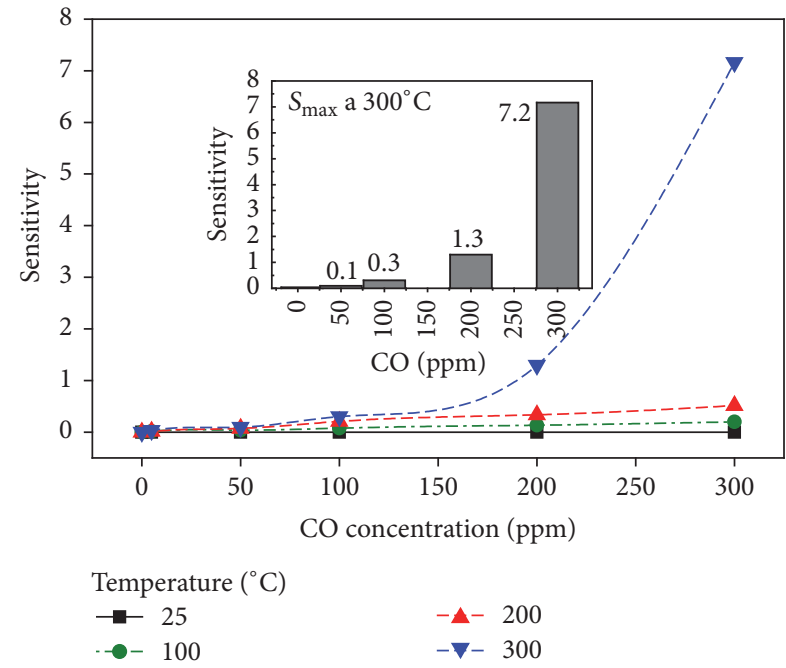

(a)

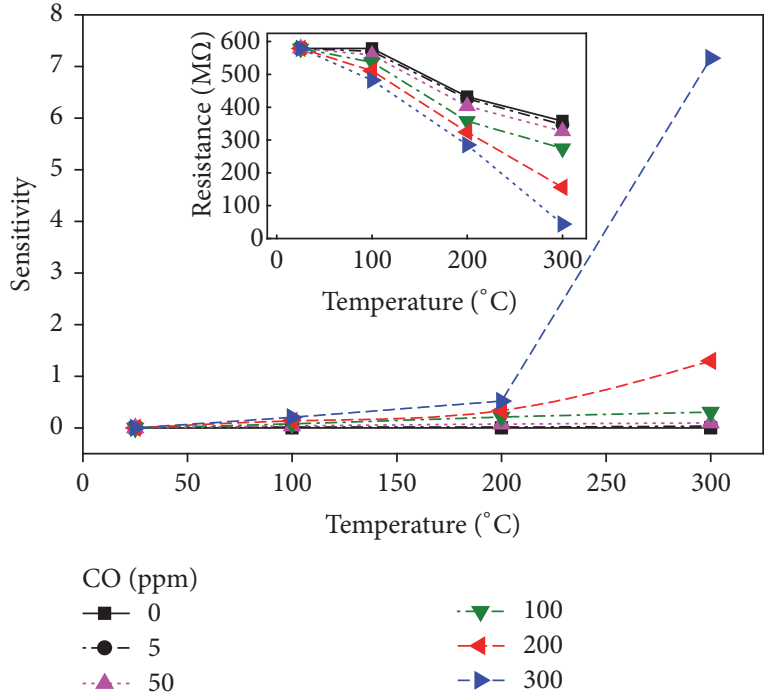

(b)

Figure 8: Sensitivity of $\mathrm{NdCoO}_{3}$ versus (a) CO concentration and (b) operating temperature.

TABle 2: Sensitivity $(S)$ values of $\mathrm{NdCoO}_{3}$ in $\mathrm{CO}$ atmospheres at 200 and $300^{\circ} \mathrm{C}$.

\begin{tabular}{ccc}
\hline Temperature $\left({ }^{\circ} \mathrm{C}\right)$ & CO concentration $(\mathrm{ppm})$ & $S$ \\
\hline \multirow{4}{*}{200} & 0 & 0 \\
& 5 & 0.02 \\
& 50 & 0.07 \\
& 100 & 0.21 \\
& 200 & 0.33 \\
& 300 & 0.52 \\
\hline \multirow{3}{*}{300} & 0 & 0 \\
& 5 & 0.03 \\
& 50 & 0.10 \\
& 100 & 0.30 \\
& 200 & 1.3 \\
& 300 & 7.2 \\
\hline
\end{tabular}

the changes in the electrical resistance of the material at different temperatures in the presence of $\mathrm{CO}$. In particular, at $100^{\circ} \mathrm{C}$, the calculated sensitivity values were $0,0.01,0.04$, $0.08,0.13$, and 0.20 in the presence of $0,5,50,100,200$, and $300 \mathrm{ppm}$ of $\mathrm{CO}$, respectively; at $200^{\circ} \mathrm{C}$, the magnitude of the sensitivity rose to $0,0.02,0.07,0.21,0.33$, and 0.52 , respectively, under the same gas concentrations; at $300^{\circ} \mathrm{C}$ the sensitivity increased to the values of $0,0.03,0.10,0.30,1.3$, and 7.2 with the same $\mathrm{CO}$ concentrations. Table 2 summarizes the sensitivity variations in $\mathrm{CO}$ at 200 and $300^{\circ} \mathrm{C}$. The most accepted mechanism to explain this phenomenon is based on the band bending caused by oxygen adsorption [39]. In this model, the oxygen adsorbed on the surface of the semiconductor captures electrons from the solid, forming the chemisorbed species $\mathrm{O}^{-}$and $\mathrm{O}^{2-}$, decreasing the number of the charge carriers $[40,41]$. The magnitude of the sensitivity clearly rises with the increase in the gas concentration. This is because the number of $\mathrm{CO}$ molecules that react with the chemisorbed oxygen increases, donating electrons to the material's surface [41]. At higher temperatures $\left(300^{\circ} \mathrm{C}\right.$ in this case), the more reactive oxygen species $\left(\mathrm{O}^{-}\right)$predominate; therefore, their formation increases the gas-solid interactions in the presence of $\mathrm{CO}$, causing a significant increase in the response. The highest measured sensitivity was 7.2 at $300 \mathrm{ppm}$ of $\mathrm{CO}$ and at a temperature of $300^{\circ} \mathrm{C}$ (Figure 8(a), inset).

Figure 9 shows the sensitivity of $\mathrm{NdCoO}_{3}$ as a function of (a) propane concentration and (b) operation temperature. A similar behavior was previously observed (in CO). Inset in Figure 9(b) shows the changes in the electrical resistance of the material at different temperatures in the presence of propane. The perovskite is sensitive to variations in the concentration of propane, obtaining the values of $0,0,0.01$, $0.02,0.03$, and 0.04 at concentrations of $0,5,50,100,200$, and $300 \mathrm{ppm}$ at $100^{\circ} \mathrm{C}$; at $200^{\circ} \mathrm{C}$, the sensitivity increased to 0 , $0.003,0.01,0.03,0.05$, and 0.07 , respectively, at the same gas concentrations; at $300^{\circ} \mathrm{C}$ the values rose to $0,0.04,0.15,0.63$, 5.4, and 94.1, respectively, at the same propane concentrations. Again, the highest sensitivity (94.1) was found at a temperature of $300^{\circ} \mathrm{C}$ at $300 \mathrm{ppm}$ of the gas (Figure 9(a), inset). Table 3 summarizes the sensitivity variations in propane at 200 and $300^{\circ} \mathrm{C}$. The propane detection mechanism has not been deeply studied so far. It has been suggested that the propane molecules react with the chemisorbed $\mathrm{O}^{-}$oxygen species producing $\mathrm{CO}_{2}$, water vapor, and a release of electrons to the material's surface resulting in variations in its electrical resistance and therefore in the sensitivity [42]. Furthermore, the sensitivity of the material decreased when the test gases were removed from the chamber, meaning that the pellets possess a high performance for different gas concentrations at different working temperatures.

The gas sensitivity results were compared with similar metal oxides finding that we have succeeded in obtaining a 


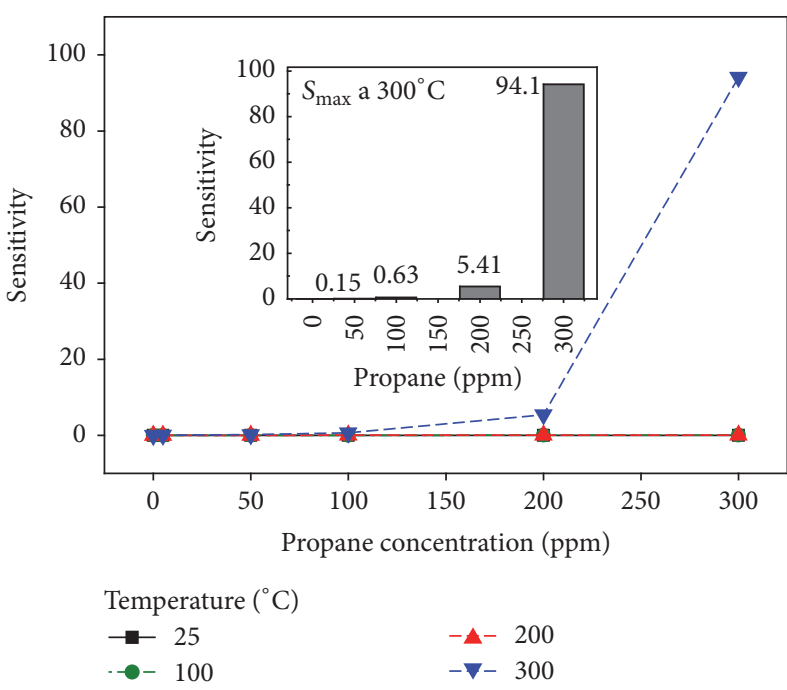

(a)

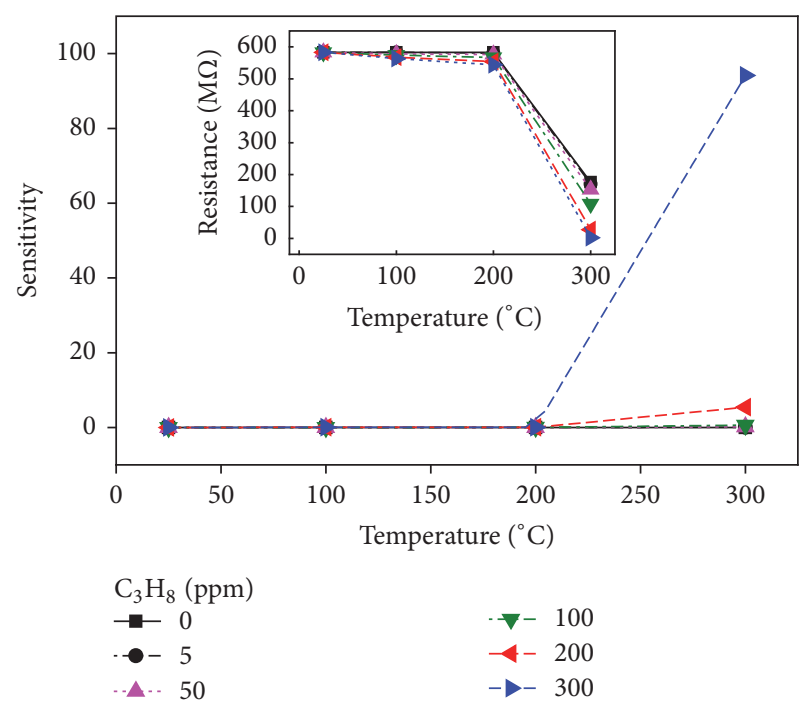

(b)

Figure 9: Sensitivity of $\mathrm{NdCoO}_{3}$ versus (a) propane concentration and (b) operating temperature.

TABLE 3: Sensitivity $(S)$ values of $\mathrm{NdCoO}_{3}$ in propane atmospheres at 200 and $300^{\circ} \mathrm{C}$.

\begin{tabular}{ccc}
\hline Temperature $\left({ }^{\circ} \mathrm{C}\right)$ & Propane concentration $(\mathrm{ppm})$ & $S$ \\
\hline \multirow{4}{*}{200} & 0 & 0 \\
& 5 & 0.003 \\
& 50 & 0.01 \\
& 100 & 0.03 \\
& 200 & 0.05 \\
300 & 300 & 0.07 \\
\hline \multirow{4}{*}{30} & 0 \\
& 5 & 0.04 \\
& 50 & 0.15 \\
& 100 & 0.63 \\
& 200 & 5.4 \\
& 300 & 94.1 \\
\hline
\end{tabular}

better response. For example, $\mathrm{ZnSb}_{2} \mathrm{O}_{6}$ microrods showed a sensitivity of $\sim 6.7$ and $\sim 1.3$ at $250^{\circ} \mathrm{C}$ in the presence of $300 \mathrm{ppm}$ of $\mathrm{CO}$ and propane, respectively [36]. Mesoporous $\mathrm{CoSb}_{2} \mathrm{O}_{6}$ nanoparticles presented maximum sensitivity values of $\sim 7$ (CO) and $\sim 4.8$ (propane) at $350^{\circ} \mathrm{C}$ and a gas concentration of $300 \mathrm{ppm}$ [37]. A sensitivity of $\sim 17$ (CO) and $\sim 31$ (propane) was reached for $\mathrm{LaFeO}_{3}$ nanoparticles at $350^{\circ} \mathrm{C}$ and a gas concentration of 200 and $300 \mathrm{ppm}$, respectively [43]. On the other hand, undoped $\mathrm{SnO}_{2}$ and $\mathrm{ZnO}$ thin films showed sensitivities of 0.7 and 2.5 , respectively, at $300^{\circ} \mathrm{C}$ and a propane concentration of $300 \mathrm{ppm}[44,45]$. The good response of the $\mathrm{NdCoO}_{3}$ toward gases can be attributed to the microstructure obtained during the synthesis process. It should be mentioned that among the different type of gas sensors (e.g., catalytic combustion, electrochemical, infrared absorption, and thermal conductive), conductometric sensors based on metal oxides have many advantages, such as ease of use, rapid response time, low detection limits, and high sensitivity (verified during this work) [46].

\section{Conclusions}

In summary, $\mathrm{NdCoO}_{3}$ perovskite-type nanoparticles were successfully synthesized by the solution method assisted by microwave radiation. This method is a sustainable and alternative route to synthesize $\mathrm{NdCoO}_{3}$ at a relatively low temperature compared with those used by other synthesis methods, mainly solid-state reactions. The characterization was conducted with X-ray diffraction, scanning and transmission electron microscopy, atomic force microscopy, energy dispersive X-ray spectroscopy, and $\mathrm{N}_{2}$ adsorption. The nanoparticles, with a high connectivity between them, formed a porous structure sensitive to changes in the concentration of carbon monoxide and propane at different operating temperatures. The sensitivity of the material rose with the increasing of the temperature and the gas concentration. The maximum values of sensitivity were found at $300^{\circ} \mathrm{C}$ and $300 \mathrm{ppm}$ for both gases. For carbon monoxide, the maximum sensitivity was found of about 7 , while for propane the sensitivity markedly increased to a value of 94 . In these terms, the perovskite-type $\mathrm{NdCoO}_{3}$ is a strong candidate to be used as a gas sensor.

\section{Conflicts of Interest}

The authors declare that there are no conflicts of interest regarding the publication of this paper.

\section{Acknowledgments}

Lorenzo Gildo-Ortiz is thankful to Consejo Nacional de Ciencia y Tecnología (CONACyT) for the received postdoctoral fellowship (2016-3, 41560). Special thanks are due to Miguel 
Ángel Luna Arias, Leonardo Pérez Manzo, and Darío Pozas Zepeda for their technical assistance during the development of this work.

\section{References}

[1] C. N. R. Rao, "World of perovskite oxides: From dielectrics to superconductors," Physica C: Superconductivity and its Applications, vol. 153-55, no. 2, pp. 1762-1768, 1988.

[2] G. Peng, X. Xu, and G. Xu, "Hybrid Organic-Inorganic Perovskites Open a New Era for Low-Cost, High Efficiency Solar Cells," Journal of Nanomaterials, vol. 2015, Article ID 241853, 10 pages, 2015.

[3] H. Du, Y. Li, W. Z. Liang et al., "Impact of $\mathrm{NiO}_{x}$ buffer layers on the dielectric properties of $\mathrm{BaTiO}_{3}$ thin films on nickel substrates fabricated by polymer assisted deposition," Journal of Nanomaterials, vol. 2015, Article ID 167569, 7 pages, 2015.

[4] A. K. Azad, J. Zaini, P. I. Petra, L. C. Ming, and S. G. Eriksson, "Effect of Nd-doping on structural, thermal and electrochemical properties of $\mathrm{LaFe}_{0.5} \mathrm{Cr}_{0.5} \mathrm{O}_{3}$ perovskites," Ceramics International, vol. 42, pp. 4532-4538, 2016.

[5] Y. Tong, J. Fu, and Z. Chen, "Synthesis, characterization, and NIR reflectance of highly dispersed $\mathrm{NiTiO}_{3}$ and $\mathrm{NiTiO}_{3} / \mathrm{TiO}_{2}$ composite pigments," Journal of Nanomaterials, vol. 2016, Article ID 5464978, 6 pages, 2016.

[6] P. H. T. Ngamou and N. Bahlawane, "Chemical vapor deposition and electric characterization of perovskite oxides $\mathrm{LaMO}_{3}$ $(\mathrm{M}=\mathrm{Co}, \mathrm{Fe}, \mathrm{Cr}$ and $\mathrm{Mn}$ ) thin films," Journal of Solid State Chemistry, vol. 182, no. 4, pp. 849-854, 2009.

[7] M. L. Norton and H.-Y. Tang, "Superconductivity at $32 \mathrm{~K}$ in electrocrystallized Ba-K-Bi-O," Chemistry of Materials, vol. 3, no. 3, pp. 431-434, 1991.

[8] H. Abdullah, M. S. Zulfakar, and S. K. Chen, "Effect of Mn-site for $\mathrm{Al}$ substitution on structural, electrical and magnetic properties in $\mathrm{La}_{0.67} \mathrm{Sr}_{0.33} \mathrm{Mn}_{1-x} \mathrm{Al}_{x} \mathrm{O}_{3}$ thin films by sol-gel method," Journal of Nanomaterials, vol. 2014, Article ID 703072, 9 pages, 2014.

[9] A. Baiker, P. E. Marti, P. Keusch, E. Fritsch, and A. Reller, "Influence of the $A$-site cation in $A_{\mathrm{CoO}_{3}}(A=\mathrm{La}, \mathrm{Pr}, \mathrm{Nd}$, and Gd) perovskite-type oxides on catalytic activity for methane combustion," Journal of Catalysis, vol. 146, no. 1, pp. 268-276, 1994.

[10] L. Fu and J.-F. Li, "Preparation and thermoelectric properties of LaCoO3 ceramics," Key Engineering Materials, vol. 434-435, pp. 404-408, 2010.

[11] A. V. Salker, N.-J. Choi, J.-H. Kwak, B.-S. Joo, and D.-D. Lee, "Thick films of In, Bi and Pd metal oxides impregnated in $\mathrm{LaCoO}_{3}$ perovskite as carbon monoxide sensor," Sensors and Actuators, B: Chemical, vol. 106, no. 1, pp. 461-467, 2005.

[12] S. Ricote, N. Bonanos, F. Lenrick, and R. Wallenberg, " $\mathrm{LaCoO}_{3}$ : Promising cathode material for protonic ceramic fuel cells based on a $\mathrm{BaCe}_{0.2} \mathrm{Zr}_{0.7} \mathrm{Y}_{0.1} \mathrm{O}_{3-\delta}$ electrolyte," Journal of Power Sources, vol. 218, pp. 313-319, 2012.

[13] D. K. Chakrabarty and D. Y. Rao, "Carbon monoxide oxidation on cobaltites of the lanthanides: effect of A-site substitution," Reaction Kinetics and Catalysis Letters, vol. 33, no. 1, pp. 131-136, 1987.

[14] A. Y. Zuev, V. V. Sereda, and D. S. Tsvetkov, "Defect structure and defect-induced expansion of doped perovskite
$\mathrm{La}_{0.7} \mathrm{Sr}_{0.3} \mathrm{Co}_{0.9} \mathrm{Fe}_{0.1} \mathrm{O}_{3-\delta}$," International Journal of Hydrogen Energy, vol. 39, no. 36, pp. 21553-21560, 2014.

[15] J. C. Ruiz-Morales, J. Canales-Vázquez, J. Peña-Martínez, D. Marrero-López, J. T. S. Irvine, and P. Núñez, "Microstructural optimisation of materials for SOFC applications using PMMA microspheres," Journal of Materials Chemistry, vol. 16, no. 6, pp. 540-542, 2006.

[16] C. J. Belle, A. Bonamin, U. Simon et al., "Size dependent gas sensing properties of spinel iron oxide nanoparticles," Sensors and Actuators, B, vol. 160, no. 1, pp. 942-950, 2011.

[17] D. D. Athayde, D. F. Souza, A. M. A. Silva et al., "Review of perovskite ceramic synthesis and membrane preparation methods," Ceramics International, vol. 42, pp. 6555-6571, 2016.

[18] E. Matijević, "Preparation and properties of uniform size colloids," Chemistry of Materials, vol. 5, no. 4, pp. 412-426, 1993.

[19] J. W. Fergus, "Perovskite oxides for semiconductor-based gas sensors," Sensors and Actuators, B: Chemical, vol. 123, no. 2, pp. 1169-1179, 2007.

[20] L. Malavasi, C. Tealdi, G. Flor et al., " $\mathrm{NdCoO}_{3}$ perovskite as possible candidate for $\mathrm{CO}$-sensors: thin films synthesis and sensing properties," Sensors and Actuators, B: Chemical, vol. 105, no. 2, pp. 407-411, 2005.

[21] H. J. Jung, J.-T. Lim, S. H. Lee, Y.-R. Kim, and J.-G. Choi, "inetics and mechanisms of $\mathrm{CO}$ oxidation on $\mathrm{Nd}_{1-x} \mathrm{Sr}_{x} \mathrm{CoO}_{3-y}$ catalysts with static and flow methods," Journal of Physical Chemistry, vol. 100, no. 24, pp. 10243-10248, 1996.

[22] C. R. Michel, E. Delgado, G. Santillán, A. H. Martínez, and A. Chávez-Chávez, "An alternative gas sensor material: synthesis and electrical characterization of $\mathrm{SmCoO}_{3}$," Materials Research Bulletin, vol. 42, no. 1, pp. 84-93, 2007.

[23] K. Wetchakun, T. Samerjai, and N. Tamaekong, "Semiconducting metal oxides as sensors for environmentally hazardous gases," Sensors and Actuators B: Chemical, vol. 160, no. 1, pp. 580-591, 2011.

[24] H. Wang, G. Li, and L. Li, "Molten-salt-mediated synthesis and low-temperature electrical conduction of $\mathrm{LnCoO}_{3}(\mathrm{Ln}=\mathrm{Pr}, \mathrm{Nd}$, Sm, and Gd)," Journal of Alloys and Compounds, vol. 612, pp. 227-232, 2014.

[25] H. Hashimoto, T. Kusunose, and T. Sekino, "Influence of ionic sizes of rare earths on thermoelectric properties of perovskitetype rare earth cobalt oxides $\mathrm{RCoO}_{3}(\mathrm{R}=\mathrm{Pr}, \mathrm{Nd}, \mathrm{Tb}, \mathrm{Dy})$," Journal of Alloys and Compounds, vol. 484, no. 1-2, pp. 246-248, 2009.

[26] C. Tealdi, M. S. Islam, C. A. J. Fisher, L. Malavasi, and G. Flor, "Defect and transport properties of the $\mathrm{NdCoO}_{3}$ catalyst and sensor material," Progress in Solid State Chemistry, vol. 35, no. 2-4, pp. 491-499, 2007.

[27] V. R. Choudhary and K. C. Mondal, " $\mathrm{CO}_{2}$ reforming of methane combined with steam reforming or partial oxidation of methane to syngas over $\mathrm{NdCoO}_{3}$ perovskite-type mixed metal-oxide catalyst," Applied Energy, vol. 83, no. 9, pp. 1024-1032, 2006.

[28] C. R. Michel, A. H. Martínez, F. Huerta-Villalpando, and J. P. Morán-Lázaro, "Carbon dioxide gas sensing behavior of nanostructured $\mathrm{GdCoO}_{3}$ prepared by a solution-polymerization method," Journal of Alloys and Compounds, vol. 484, no. 1-2, pp. 605-611, 2009.

[29] V. V. Gorbunov, A. A. Shidlovskii, and L. F. Shmagin, "Combustion of transition-metal ethylenediamine nitrates," Combustion, Explosion, and Shock Waves, vol. 19, no. 2, pp. 172-173, 1983. 
[30] L. Gildo-Ortiz, H. Guillén-Bonilla, and J. Santoyo-Salazar, "Low-temperature synthesis and gas sensitivity of perovskitetype $\mathrm{LaCoO}_{3}$ nanoparticles," Journal of Nanomaterials, vol. 2014, Article ID 164380, 8 pages, 2014.

[31] O. Mihai, D. Chen, and A. Holmen, "Chemical looping methane partial oxidation: the effect of the crystal size and $\mathrm{O}$ content of $\mathrm{LaFeO}_{3}$," Journal of Catalysis, vol. 293, pp. 175-185, 2012.

[32] Y. Yamada, K. Yano, D. Hong, and S. Fukuzumi, " $\mathrm{LaCoO}_{3}$ acting as an efficient and robust catalyst for photocatalytic water oxidation with persulfate," Physical Chemistry Chemical Physics, vol. 14, no. 16, pp. 5753-5760, 2012.

[33] Z.-X. Deng, C. Wang, X.-M. Sun, and Y.-D. Li, "Structuredirecting coordination template effect of ethylenediamine in formations of $\mathrm{ZnS}$ and $\mathrm{ZnSe}$ nanocrystallites via solvothermal route," Inorganic Chemistry, vol. 41, no. 4, pp. 869-873, 2002.

[34] X. Wang and Y. Li, "Solution-based synthetic strategies for 1-D nanostructures," Inorganic Chemistry, vol. 45, no. 19, pp. 75227534, 2006.

[35] H. Guillén-Bonilla, M. Flores-Martínez, V.-M. RodríguezBetancourtt et al., "A novel gas sensor based on $\mathrm{MgSb}_{2} \mathrm{O}_{6}$ nanorods to indicate variations in carbon monoxide and propane concentrations," Sensors (Switzerland), vol. 16, no. 2, article 177, pp. 1-12, 2016.

[36] H. Guillen-Bonilla, V.-M. Rodríguez-Betancourtt, J.-T. GuillénBonilla et al., " $\mathrm{CO}$ and $\mathrm{C}_{3} \mathrm{H}_{8}$ sensitivity behavior of zinc antimonate prepared by a microwave-assisted solution method," Journal of Nanomaterials, vol. 2015, Article ID 979543, 8 pages, 2015.

[37] H. Guillén-Bonilla, L. Gildo-Ortiz, M. L. Olvera-Amador et al., "Sensitivity of mesoporous $\mathrm{CoSb}_{2} \mathrm{O}_{6}$ nanoparticles to gaseous $\mathrm{CO}$ and $\mathrm{C}_{3} \mathrm{H}_{8}$ at low temperatures," Journal of Nanomaterials, vol. 2015, Article ID 308465, 9 pages, 2015.

[38] V. K. Lamer and R. H. Dinegar, "Theory, production and mechanism of formation of monodispersed hydrosols," Journal of the American Chemical Society, vol. 72, no. 11, pp. 4847-4854, 1950.

[39] C. Wang, L. Yin, L. Zhang, D. Xiang, and R. Gao, "Metal oxide gas sensors: sensitivity and influencing factors," Sensors, vol. 10, no. 3, pp. 2088-2106, 2010.

[40] S. C. Chang, "Oxygen chemisorption on tin oxide: correlation between electrical conductivity and EPR measurements," Journal of vacuum science \& technology, vol. 17, no. 1, pp. 366-369, 1979.

[41] M. Siemons and U. Simon, "High throughput screening of the sensing properties of doped $\mathrm{SmFeO}_{3}$," Solid State Phenomena, vol. 128, pp. 225-236, 2007.

[42] V. K. Jayaraman, A. Maldonado Álvarez, and M. De la Luz Olvera Amador, "A simple and cost-effective zinc oxide thin film sensor for propane gas detection," Materials Letters, vol. 157, Article ID 18958, pp. 169-171, 2015.

[43] L. Gildo-Ortiz, J. Reyes-Gómez, J. M. Flores-Álvarez et al., "Synthesis, characterization and sensitivity tests of perovskitetype $\mathrm{LaFeO}_{3}$ nanoparticles in $\mathrm{CO}$ and propane atmospheres," Ceramics International, vol. 42, no. 16, pp. 18821-18827, 2016.

[44] H. Gómez-Pozos, J. L. González-Vidal, G. A. Torres, M. de la Luz Olvera, and L. Castañeda, "Physical characterization and effect of effective surface area on the sensing properties of tin dioxide thin solid films in a propane atmosphere," Sensors, vol. 14, no. 1, pp. 403-415, 2013.
[45] H. Gómez-Pozos, J. L. González-Vidal, and G. A. Torres, "Chromium and ruthenium-doped zinc oxide thin films for propane sensing applications," Sensors, vol. 13, no. 3, pp. 34323444, 2013.

[46] G. Korotcenkov, "Metal oxides for solid-state gas sensors: what determines our choice?" Materials Science and Engineering B: Advanced Functional Solid-State Materials, vol. 139, no. 1, pp. 123, 2007. 

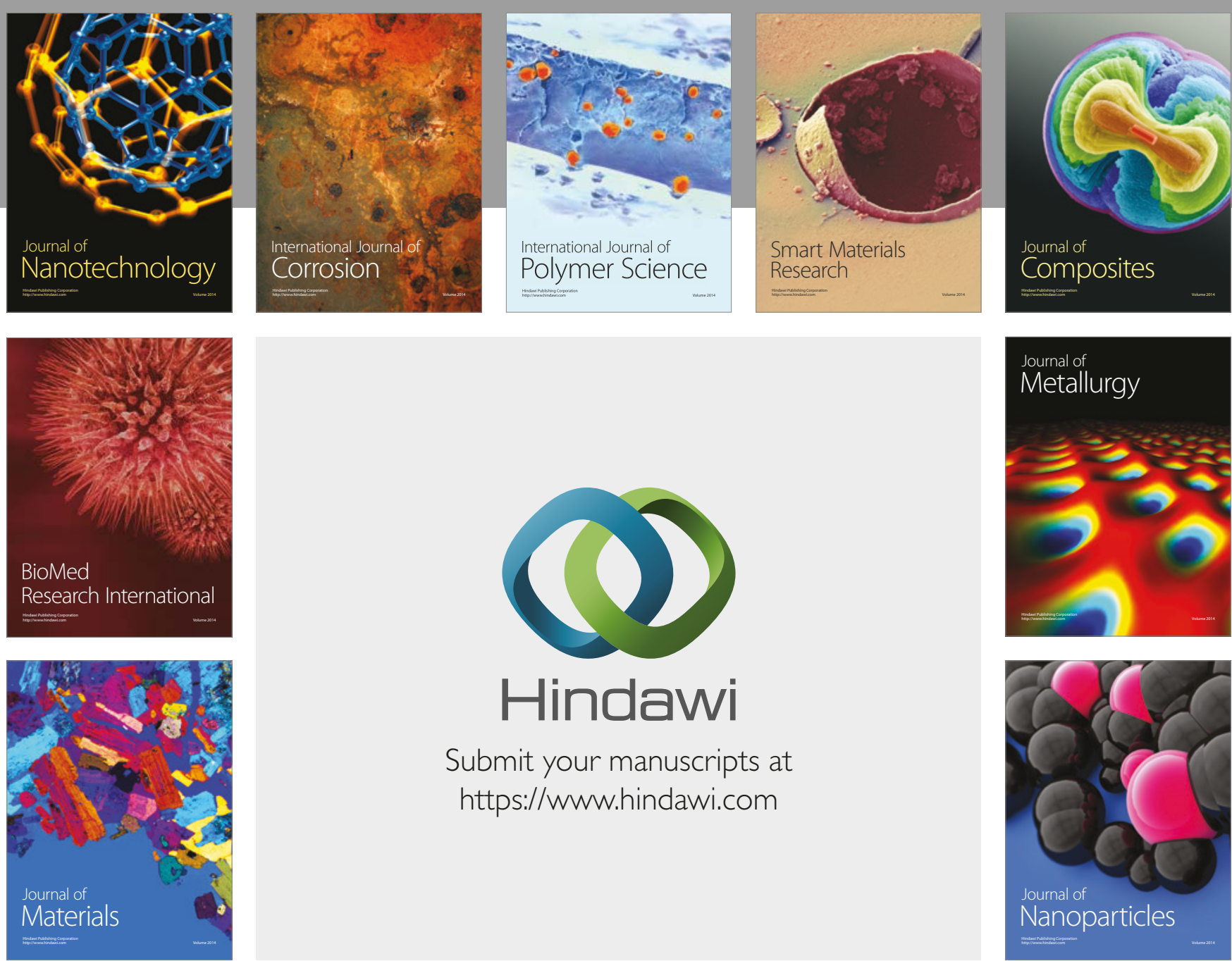

\section{Hindawi}

Submit your manuscripts at

https://www.hindawi.com
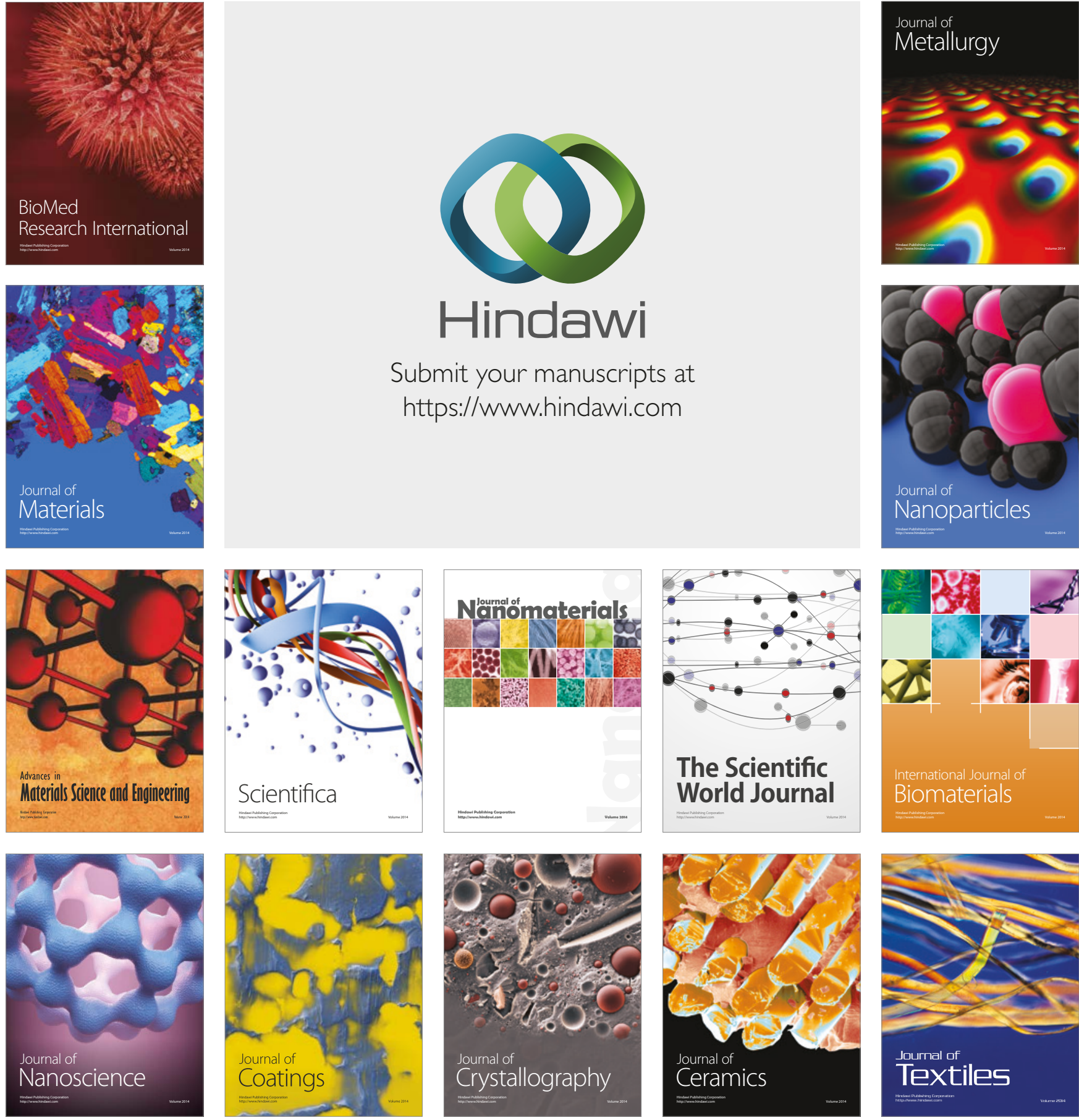

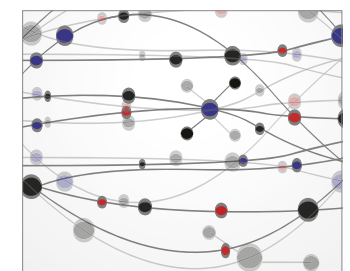

The Scientific World Journal
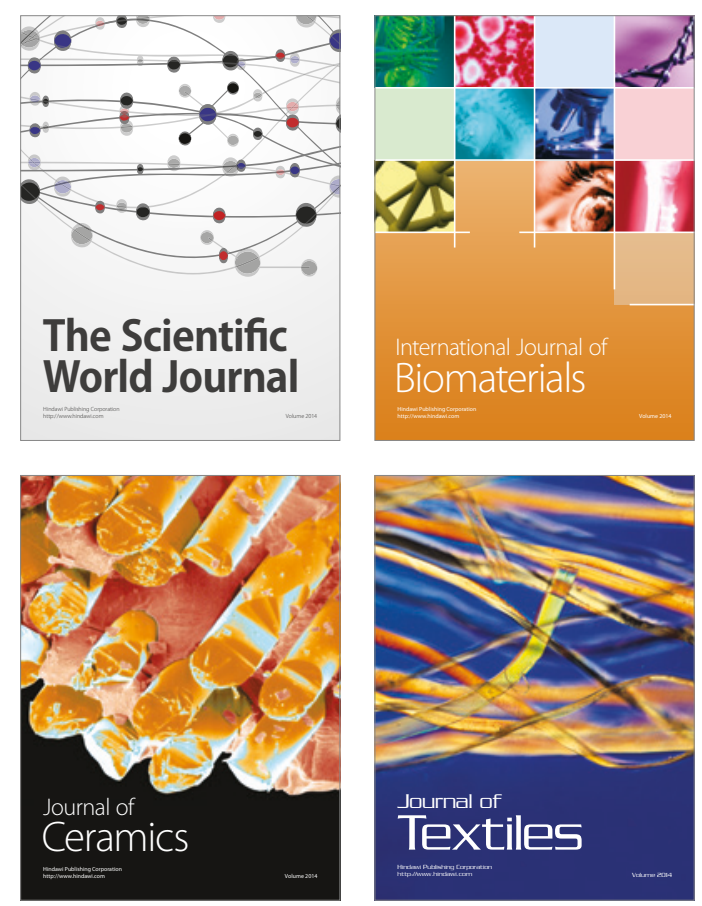